\title{
Novo ensino médio e educação integral: contextos, conceitos e polêmicas sobre a reforma
}

\author{
Karen Cristina Jensen Ruppel da Silva* \\ Universidade Estadual de Ponta Grossa \\ Aldimara Catarina Boutin** \\ Universidade Estadual de Ponta Grossa
}

Resumo O presente artigo propõe estabelecer reflexões sobre a proposta de educação integral expressa na atual Reforma do Ensino Médio, instituída por meio da Lei no $13.415 / 2017$, e desse modo trazer argumentos para instigar o debate teórico acerca do assunto. Os objetivos que norteiam o trabalho são: a) Investigar as proposições para a educação integral que norteiam a proposta do Novo Ensino Médio; b) Analisar o contexto em que surgiu a reforma do Novo Ensino Médio, os conceitos de educação integral e alguns pontos de maior controvérsia entre defensores e críticos da nova lei. As análises têm como suporte teórico e metodológico o materialismo histórico e dialético, e pautam-se em pesquisa bibliográfica e documental. Para a coleta de dados foram utilizados decretos, leis, livros e artigos que tratavam do objeto em análise. O diálogo teórico se valeu da contribuição de autores como: Tonet (2013); Mészaros (2014); Marx e Engels (2006); Ferreira JR e Bittar (2008), entre outros que oferecem contribuições para a compreensão da política educacional analisada. Os resultados da pesquisa explicitaram os limites que pautam a atual reforma do Ensino Médio proposta por meio da Lei no 13.415/2017. Foi possível perceber que a reforma que integra a educação integral no chamado Novo Ensino Médio tem como compromisso uma formação mais técnica e menos propedêutica, servindo dessa forma ao jogo de interesses que rege a sociedade do capital, uma vez que contribui para a formação do homem produtivo, do homem massa, distanciando-se do conceito de omnilateralidade que pressupõe uma formação efetivamente integral.

PALAVRAS-ChAVE: Educação; Educação integral; Ensino médio; Reformas educacionais. 


\section{New middle school and integral education: contexts, concepts and policies on reform}

Abstract The present article proposes to establish reflections on the proposal of integral education expressed in the current High School Reform, instituted through Law $n^{\circ} 13.415$ / 2017, and in this way to bring arguments to instigate the theoretical debate about the subject. The objectives that guide the work are: a) To investigate the proposals for integral education that guide the proposal of the New High School; b) Analyze the context in which the reform of the New High School, the concepts of integral education and some points of greater controversy between defenders and critics of the new law arose. The analyzes have as theoretical and methodological support historical and dialectical materialism and are based on bibliographic and documentary research. For the collection of data were used decrees, laws, books and articles dealing with the object under analysis. The theoretical dialogue was based on the contribution of authors such as: Tonet (2013); Mészaros (2014); Marx and Engels (2006); Ferreira JR and Bittar (2008), among others that offer contributions to the understanding of the educational policy analyzed. The results of the research made explicit the limits that govern the current reform of the High School proposed by means of Law $\mathrm{n}^{\circ} 13.415$ / 2017. It was possible to perceive that the reform that integrates integral education in the so-called New High School has as commitment a more technical and less propaedeutic formation, serving in this way the game of interests that governs the society of capital, since it contributes to the formation of the man productive, of the mass man, distancing himself from the concept of omnilaterality that presupposes an effectively integral formation.

KEYWORDS: Education; Integral education; High school; Educational reforms.

\section{Introdução}

Temos vivenciado tempos de instabilidade política em nosso país e, meio a um turbilhão de acontecimentos no cenário político e econômico, ações ${ }^{1}$ que alteram significativamente a realidade têm sido tomadas de maneira rápida e sem ampla discussão com os diversos segmentos sociais. A atual Reforma do Ensino Médio, instituída por meio da Lei no 13.415/2017, é um exemplo dessas ações. A referida lei tem como proposta, entre outros pontos, reestruturar a agenda da educação integral no Brasil.

Nos últimos oito anos essa agenda foi representada pelo Programa Mais Educação. Com a ascensão de Michel Temer à presidência da república, por meio de um processo de impedimento da presidente eleita Dilma Rousseff, esse programa foi reformulado, passando a se intitular Novo Mais Educação. No entanto, o foco da atual agenda parece ter se deslocado para outra - e polêmica - proposta, o Novo Ensino Médio. 
Instituir uma reforma tão expressiva e controversa enquanto uma das primeiras ações pós-impeachment foi uma medida ousada. Desvelar porque esta Medida tramitou em caráter de urgência, e porque foram despendidos tantos esforços para a sua aprovação diante do contexto delicado em que se encontra a política brasileira, é tarefa urgente no campo das políticas educacionais. Para tanto, esboçaremos aqui o contexto em que surgiu a atual reforma do ensino médio, bem como reflexões sobre conceitos de educação integral e alguns pontos de maior controvérsia entre defensores e críticos da nova lei.

\section{Contribuições para o debate téórico sobre o novo ensino médio e educação integral}

Apesar de a polêmica ter emergido com maior intensidade em 2016, a partir da Medida Provisória 746, a atual reforma do ensino médio, instituída por meio da Lei no $13.415 / 2017$, tem sido pensada já há algum tempo por nossos legisladores. Seus pressupostos foram lançados ao público em 2013 por meio do Projeto de Lei 6.840, de autoria do deputado Reginaldo Lopes (PT-MG). O Projeto de Lei contou com a assessoria e contribuição de alguns segmentos sociais, principalmente agentes ligados ao setor privado, como representantes do Instituto Alfa e Beto, do Instituto de Estudos do Trabalho e Sociedade e do Movimento Todos Pela Educação, que endossaram a necessidade de um currículo diversificado e atrativo, uma formação mais técnica do que teórica, restrições para a oferta do ensino noturno e uma ampliação da carga horária diária (SILVA; KRAWCZYK, 2016).

Descontentes com as proposições da PL 8.460/2013 e com a falta de diálogo na tramitação do processo, educadores se uniram na criação do Movimento Nacional em Defesa do Ensino Médio, que resultou na publicação de um Manifesto apresentando os principais pontos de discordância com relação ao referido Projeto de Lei. A pressão do Movimento levou a apresentação de um substitutivo modificando alguns elementos do Projeto original como, por exemplo, a retirada da obrigatoriedade das opções formativas, da jornada em tempo integral, das proposições dos temas transversais e da restrição de idade para o ensino noturno. Mesmo com a alteração da PL, o Movimento temia que as pressões do empresariado mobilizassem os deputados a aprovarem emendas que atendessem aos interesses do setor. No entanto, a ameaça de impeachment que assombrou o país em meados de 2015, e a sua concretização em 2016, colocou a PL em hiato (SILVA; KRAWCZYK, 2016).

A reforma do ensino médio voltou à tona em setembro de 2016 por meio de uma Medida Provisória que tomou de sobressalto alunos e educadores. Diante da instabilidade do momento político, da amplitude da reforma e da ausência de uma discussão democrática, a MP não poderia gerar outra coisa senão a revolta de diversos segmentos sociais ligados à educação. Como não bastasse, tramitava, quase que ao mesmo tempo, outra proposta do governo federal que contribuiu para a efervescência do momento: a PEC no 241/ 2016 ou PEC no 55/2016, como passou a ser denominada no tramite no Senado Federal, sendo aprovada, instituiu-se a Emenda Constitucional no 95/2016. 
A insatisfação e a revolta com as reformas do governo federal pós-impeachment fomentaram diversas manifestações organizadas pela comunidade acadêmica. Um exemplo bastante expressivo dessas manifestações foi o processo de ocupação de escolas por estudantes contrários a MP 746 e a PEC 241. Essas ocupações foram ainda mais acentuadas no estado do Paraná, devido ao descaso na gestão da educação pública por parte do governo Beto Richa. De acordo com os dados divulgados pelo Movimento Ocupa Paraná (2016), o número de ocupações em outubro de 2016 chegou a 836 escolas, 13 universidades e 3 núcleos de educação em todo o estado 2 . Pressionados pelo movimento conservador ${ }^{3}$ de vários agentes sociais e pela rigidez do poder público, o movimento foi obrigado a cumprir as determinações judiciais que designaram a desocupação das escolas.

Com a repressão aos movimentos sociais e sem diálogo ampliado com a comunidade acadêmica e com os demais setores da sociedade civil, a Medida Provisória foi aprovada na câmara dos deputados em dezembro de 2016.

Já no início do ano de 2017, tramitando em caráter de urgência no senado, a aprovação da reforma do ensino médio foi uma das primeiras ações dos senadores na volta do recesso. Sem maiores impedimentos, a MP 746/2016 foi sancionada pelo presidente em exercício Michel Temer, no dia 16 de fevereiro de 2017 sob a Lei 13.415.

De acordo com o site do Ministério da Educação a consolidação do Novo Ensino Médio depende da aprovação da Base Nacional Comum, encaminhada em abril para o Conselho Nacional de Educação. Nesse sentido, a previsão é que a proposta se efetive entre os anos de 2018 e 2019. (MINISTÉRIO DA EDUCAÇÃO..., 2017).

\begin{abstract}
A BNCC será obrigatória e irá nortear os currículos das escolas de ensino médio. Após essa etapa, no primeiro ano letivo subsequente à data de publicação da BNCC, os sistemas de ensino deverão estabelecer um cronograma de implantação das principais alterações da lei e iniciar o processo de implementação, conforme o referido cronograma, a partir do segundo ano letivo (MINISTÉRIO DA EDUCAÇẨO..., 2017).
\end{abstract}

Analisando o contexto de surgimento dessa reforma, levando em conta a urgência em que tramitou a proposta e os interesses do setor privado em sua aprovação, fica evidente que a educação integral do jovem brasileiro não é a única, nem sequer a principal, intenção do Novo Ensino Médio. Importa agora problematizar o conceito de educação integral defendido nessa proposta.

$\mathrm{Na}$ contemporaneidade, e mais especificamente no contexto brasileiro, o conceito de educação integral está diretamente atrelado à ideia de tempo escolar ampliado, tanto ao que diz respeito à quantidade de dias letivos, como também, e principalmente, ao aumento da carga horária diária que um mesmo aluno passa na escola. Sob essa perspectiva, a Portaria 1.145 de 10 de outubro de 2016 instituiu o Programa de Fomento à Implementação de Escolas de Tempo Integral, criado por meio da Medida Provisória no 746 de 22 de setembro de 2016. Segundo esta Portaria: 
§ 1o A proposta pedagógica das escolas de ensino médio em tempo integral terá por base a ampliação da jornada escolar e a formação integral e integrada do estudante, tanto nos aspectos cognitivos quanto nos aspectos socioemocionais, observados os seguintes pilares: aprender a conhecer, a fazer, a conviver e a ser (BRASIL, 2016).

A forma como o texto se apresenta aponta que a "formação integral e integrada” fazem parte de um projeto cuja centralidade é a ampliação da jornada escolar. O próprio título da proposta a denuncia neste sentido Programa de Fomento à Implementação de Escolas de Tempo Integral. Essa tem sido uma característica marcante na agenda de educação integral no Brasil, onde o foco está muito mais no tempo ampliado do que na formação integral do ser humano. Deste modo, a formação integral e integrada parece estar em segundo plano, uma vez que não é o tempo ampliado que está em prol da educação integral, mas ao contrário, a educação dita integral parece ser uma manobra pra contemplar o tempo ampliado.

A atual proposta de reforma do ensino médio, aparentemente, trata-se de mais uma política na agenda da educação integral que visa muito mais a necessidade de ampliar o tempo do que de ampliar as possibilidades educativas comprometidas com a formação mais completa do educando, demonstrando que o que se deseja é, na verdade, um aluno por mais tempo na escola. Sob esta perspectiva, é possível concordar com Moll (2012, p. 129) quando esta afirma que no Brasil educação integral é "compreendida como educação escolar de dia inteiro, constituída e enriquecida por significativas possibilidades formativas", no entanto, essas "significativas possibilidades formativas" não se constituem enquanto a essência dessas políticas.

Levando em conta que educação integral e educação de tempo integral são conceitos diferentes, cabe pensar à qual projeto de sociedade interessa o aluno mais tempo na escola e porque a educação mais completa não é verdadeiramente compreendida neste projeto. Para tanto, se faz imprescindível, esclarecer o que é educação integral.

É possível evidenciar dois polos, não só diferentes, mas também antagônicos, sobre o conceito de educação integral. No primeiro, encontram-se perspectivas que visam romper com o modelo de produção e organização social vigente. No segundo, entendido como expressão da concepção hegemônica, situam-se perspectivas que buscam manter e reformar a atual forma de sociabilidade. Sobre este último polo:

[...] as concepções de educação integral que colaboram com a manutenção da sociedade do capital, se constituem como hegemônicas e se baseiam em ideários neoliberais e escolanovistas. Nesta perspectiva, utilizam-se frequentemente os termos ressignificação, reconstrução, reinvenção, que colaboram com a ideia de reforma, de dar novo significado ao já existente, sem uma transformação fundamental na base. A ideia de educação para paz e para a convivência solidária também ganha força neste discurso e pode cair como uma luva para a necessária conformação com a ordem vigente, afastando a perspectiva de luta de classes e negativando a ideia de uma possível revolução. A proposta do desenvolvimento das potencialidades do educando também é enaltecida, porém numa perspectiva micro, onde a individualidade e as experiências subjetivas são postas em 
evidência, como se a partir do momento em que o sujeito estivesse bem consigo mesmo - em seus aspectos físicos, cognitivos, afetivos etc. - estaria automaticamente bem com os demais sujeitos e com o mundo, e assim todos os problemas sociais seriam minimizados nesta relação entre sujeito e seu interior, e a harmonia poderia então vigorar plena (SILVA, 2016, p. 34).

Essa concepção hegemônica ${ }^{4}$ considera que a sociedade precisa de alguns ajustes e não de uma transformação basilar, respalda-se em ideários que confirmam essa premissa, como o neoliberalismo e escolanovismo. A educação é, nessa concepção, um elemento chave para as mudanças necessárias. Sob esta ótica, a educação integral seria aquela que promove novo significado a escola, que valoriza a singularidade dos sujeitos, desenvolvendo as relações cordiais e solidárias para uma sociedade cada vez mais harmoniosa.

$\mathrm{Na}$ contramão dessa perspectiva, o conceito de educação integral sob a perspectiva da omnilateralidade centra-se na necessidade e contingência de um rompimento com o status quo, sem o qual a impossibilidade da educação integral é imperante.

De acordo com Mézáros (2014, p. 15) a "natureza da educação - como tantas outras coisas essenciais nas sociedades contemporâneas - está vinculada ao destino do trabalho", com essa afirmação o autor ressalta a estreita relação entre educação e o modelo econômico de uma sociedade; "digam-me onde está o trabalho em um tipo de sociedade e eu te direi onde está a educação” (MÉSZÁROS, 2014, p. 17).

Em consonância com Mészáros, Saviani (1994) entende que, historicamente, a educação vem cumprindo diferentes papéis. $\mathrm{O}$ autor expõe que a educação se diferencia de acordo com o modo de produção vigente, havendo dessa forma uma estreita relação entre o surgimento da educação escolar e o nascimento de uma classe proprietária, o que contribuiu para que a educação formal se tornasse um processo fragmentado, unilateral, modelo que ainda hoje vigora. No entanto vale lembrar que nem sempre foi assim, já que a educação não é um processo natural, mas algo socialmente construído.

No comunismo primitivo a educação podia ser considerada como integral e espontânea. Integral, porque compreendia mais ou menos todo o conhecimento que o gênero humano tinha desenvolvido até então. Espontânea, porque ocorria no próprio processo de trabalho, não havia uma pessoa responsável por essa educação, nem um lugar e um currículo específico pra que ela acontecesse. Com a apropriação privada da terra, que dividiu os homens em classes - proprietários e não proprietários - surgiu a educação escolar. Uma educação diferenciada para aqueles que dispunham de tempo ocioso - proprietários - os demais, continuavam a se educar no próprio processo de trabalho. Com o desenvolvimento das forças produtivas ocorrem mudanças no modelo econômico, que vai se tornando cada vez mais complexo. Um modo de produção mais complexo exige trabalhadores mais complexos. A qualificação desses trabalhadores fica então a cargo da escola, e assim a escola se abre para as massas (PONCE, 1957; SAVIANI, 1994). 
Infere-se assim, que desde o surgimento da propriedade privada a educação deixa de ser integral, e passa a ser unilateral, atendendo as demandas do modelo econômico. Mesmo a educação dos proprietários é unilateral, pois, distanciado do processo de trabalho, não compreende as múltiplas possibilidades de conhecimento desenvolvidas pelo gênero humano.

$\mathrm{O}$ que se legitima neste projeto como educação integral é justamente o oposto da educação unilateral, é a defesa da omnilateralidade, conceito amplo e complexo na teoria marxista, que se refere ao desenvolvimento das potencialidades humanas ao associar tempo livre e tempo de trabalho, comportando "elementos de disponibilidade, variação e multilateralidade, como, também, a posse de capacidades teóricas e práticas" (FERREIRA JR; BITTAR, 2008, p. 644). Trata-se de uma educação humanista, comprometida com a transformação social e com o pleno desenvolvimento do homem, que congrega ensino intelectual, físico e tecnológico (FERREIRA JR; BITTAR, 2008).

No entanto, como já assinalado, onde vigora a propriedade privada desfruta-se apenas de uma educação unilateral. Assim, é possível concordar com Marx e Engels (2006) quando estes afirmam que a "história de toda a sociedade é a história da luta de classes". Ora, levando em conta essa premissa, sabendo que a luta de classes não fora superada e que a educação não está imune a essa luta, é preciso considerar as reais possibilidades da educação no processo de formação do homem na atualidade.

De acordo com Mézsáros (2014, p.15), a função da educação formal nessa sociedade é "fornecer os conhecimentos e o pessoal necessário à maquinaria produtiva em expansão do sistema capitalista, mas também gerar e transmitir um quadro de valores que legitima os interesses dominantes". Sendo esta a principal função da escola na atual forma de sociabilidade, o que nós educadores podemos então fazer?

Sob a perspectiva marxista, a categoria contradição nos ajuda a compreender algumas possibilidades. Segundo Masson (2012, p.5), é a contradição que "promove o movimento que permite a transformação dos fenômenos" já que "a presença de aspectos e tendências contrários contribui para que a realidade passe de um estado qualitativo a outro". Neste sentido, não necessitamos esperar de braços cruzados uma transformação social para que comecemos a pensar numa educação que contemple as máximas possibilidades humanas, pois esse processo "não se dará nos marcos do 'zero histórico', ou seja, o movimento em si já nasce no âmago das próprias relações capitalistas de produção" (FERREIRA JR; BITTAR, 2008, p. 645). Deste modo podemos estabelecer a educação como uma - não há única - mediação para a emancipação humana e assim para o desenvolvimento das máximas potencialidades do ser.

Tonet (2013, p. 244) nos alerta que não podemos perder de vista que "a questão decisiva é sempre o processo de autoconstrução do homem". É nesse sentido que o autor defende alguns requisitos para uma atividade educativa de caráter emancipador. São eles: a) ter clareza do fim maior da educação; b) apropriar-se do conhecimento sobre o processo histórico; c) conhecer o campo específico da educação; d) dominar os conteúdos específicos de cada área do saber; e) articular a atividade educativa com a luta da classe trabalhadora. 
A atual reforma do ensino médio se distancia a largos passos desses requisitos. $\mathrm{O}$ texto da Portaria já indica que a proposta tem por base os quatro pilares da educação, conceito oriundo da chamada Pedagogia de Competências, uma concepção reformista de educação e sociedade, que como afirma Saviani (2013, p. 437), tem por objetivo "dotar os indivíduos de comportamentos flexíveis que lhes permitam ajustarse às condições de uma sociedade". Sobre um dos mais enfatizados pilares da Pedagogia de Competências, o aprender a aprender, Duarte afirma:

[...] o lema "aprender a aprender" passa a ser revigorado nos meios educacionais, pois preconiza que à escola não caberia a tarefa de transmitir o saber objetivo, mas sim a de preparar os indivíduos para aprenderem aquilo que deles for exigido pelo processo de sua adaptação às alienadas e alienantes relações sociais que presidem o capitalismo contemporâneo. A essência do lema "aprender a aprender" é exatamente o esvaziamento do trabalho educativo escolar, transformando-o num processo sem conteúdo (DUARTE, 2004, p. 8).

A análise de Duarte aponta para a falta de conteúdo do lema "aprender a aprender", justamente o que se contrapõe aos requisitos de uma atividade educativa que tenha por interesse a emancipação humana.

Para além das questões filosóficas que embasam a reforma, existem muitos elementos de discordância com relação ao Novo Ensino Médio.

Um dos pontos de grande discussão a respeito do Novo Ensino Médio é a ampliação de 800 para 1400 horas a carga horária anual a ser cumprida pelo aluno. Cabe pensar em quem é este aluno do ensino médio brasileiro. Levando em conta os problemas socioeconômicos dos usuários da escola pública, há de se considerar que muitos jovens, matriculados no ensino médio, contribuem para a renda familiar. Um aluno trabalhador dificilmente concluiria o curso nesse novo formato proposto.

A Pesquisa Nacional por Amostra de Domicílio - Pnad, realizada em 2013 com resultados divulgados em 2014, mostrou que apenas 54\% dos jovens concluem o ensino médio até os 19 anos (TODOS PELA EDUCAÇÃO, s/d). Tratar esse dado alarmante como apenas falta de interesse, já que se tem considerado que o currículo do ensino médio não é atrativo ao jovem, é uma análise muito simplista do problema da evasão e a ampliação do tempo escolar pode vir a ser mais um agravante.

Ampliar a carga horária sem ampliar a estrutura física das escolas e o número de profissionais da educação é ampliar a precariedade. Temos vivenciado há tempos em nosso país problemas emergenciais como falta de merenda escolar e de professores, além do espaço físico muitas vezes insatisfatório, e antes de resolver problemas básicos como este, e diante da PEC 241 que congela investimentos para educação, emergiu a proposta de um aumento significativo da carga horária diária para o ensino médio. Essa política parece desconhecer a realidade das escolas brasileiras e de seus educandos. Neste aspecto, pode-se concordar com Junkes (2016) quando esta afirma que:

A escola pública de tempo integral tem como centralidade o aumento do tempo das crianças pobres e desamparadas socialmente, sob responsabilidade do poder público, e desta forma, visa atender 
suas necessidades básicas de saúde (alimentação, higiene, atividade física) e educação (moral, civil, profissional). Tais características levam a reflexão sobre o ideal formativo posto, de ampliação das oportunidades de aprendizagem, em detrimento de um atendimento precarizado, sem investimento financeiro na estrutura física e pedagógica da escola, quando destinada à classe popular (JUNCKES, 2016, p.12).

Ainda de acordo com a autora, a educação

[...] da classe popular está pautada na aprendizagem dos conteúdos curriculares mínimos e na disciplinarização de seu comportamento, visando ainda corresponder às exigências de qualificação dos índices sociopolíticos (Índices de Desenvolvimento Humano - IDH, Índices de Desenvolvimento da Educação Básica - IDEB), sendo sua formação direcionada ao futuro, à formação do bom cidadão/trabalhador (JUNCKES, 2016, p.13).

Assim, o tempo ampliado pode ser muito mais um empecilho, privando o jovem de seu tempo livre para realização de outras atividades que lhe despertem o interesse, do que de fato pode contribuir para uma formação humana mais complexa.

Outro elemento de discordância na presente reforma é a questão curricular, uma vez que a proposta parece culpar o atual currículo por todas as mazelas do ensino médio. Segundo a exposição de motivos que justifica a Medida Provisória, o resultado negativo nas avaliações externas "é reflexo de um modelo prejudicial que não favorece a aprendizagem e induz os estudantes a não desenvolverem suas habilidades e competências" (BRASIL, 2016). O mesmo documento enfatiza também a necessidade de adequar o currículo as exigências do mercado de trabalho. Nesse sentido, disciplinas como arte, filosofia, sociologia e até mesmo história e geografia perdem a estabilidade na grade curricular, já que deixam de atender aos interesses imediatos da proposta, que parece vislumbrar muito mais a formação do futuro empregado do que uma formação humana multifacetada.

Com relação aos itinerários formativos, que remetem as opções formativas do período ditatorial, apesar da propaganda que circula na mídia sobre a oportunidade de escolha pelo jovem, o texto da lei deixa claro que esses itinerários estão à critério dos sistemas de ensino, e não do aluno. Sobre os sistemas de ensino Saviani (1999, p. 122) afirma que educadores e, principalmente, os legisladores têm evitado a "questão relativa ao esclarecimento preciso do conceito de sistema" por ser considerado "algo constantemente referido mas cujo sentido permanece sempre implícito, supostamente compreendido mas jamais assumido explicitamente". Deste modo, saber a cargo de quem ficará os itinerários formativos é uma preocupação constante, já que o sistema de ensino em questão pode vir a não ofertar o itinerário formativo desejado pelo aluno, e pior ainda, o sistema de ensino pode vir a ofertar somente aqueles itinerários que os recursos, muitas vezes precários, permitirem.

Do ponto de vista da organização curricular, a MP 746/2016 retoma um modelo já experimentado nos tempos da ditadura militar, trazendo de volta a divisão por opções formativas. A formação básica comum que atualmente é garantida nos três anos do Ensino Médio 
passaria a ser dada em apenas a metade desse tempo. Após isso, o/a estudante seria dirigido a uma das ênfases (Linguagens, Matemática, Ciências da Natureza, Ciências Humanas ou formação técnico -profissional), a critério do sistema do ensino. É importante frisar: não será o estudante a escolher o itinerário com o qual possui maior afinidade. Será o sistema de ensino a definir, conforme sua própria disponibilidade, o que cada unidade escolar irá oferecer. Essa medida, além de significar uma perda de direito e um enorme prejuízo com relação à formação da nossa juventude, fere a autonomia das escolas na decisão sobre seu projeto político pedagógico, o que hoje está assegurado na Lei de Diretrizes e Bases da Educação (LDB) e que será alterada pela Medida Provisória (RIBEIRO, 2016).

Outros fatores de grande controversa são a ênfase no ensino técnico, a possibilidade de atuação de professores com notório saber e a abertura cada vez maior para as parcerias público-privadas, conforme expõe Ribeiro:

Especial atenção merece a proposta do itinerário formativo relativo à formação técnico-profissional. Por exemplo, ao propor que para ser docente nos cursos não há necessidade de formação especializada, bastando para isso que o sistema de ensino certifique um suposto "notório saber", a MP 746/2016 desconsidera que para o aprimoramento da qualidade do ensino se precisa garantir aos profissionais da educação uma sólida formação teórico-prática, preferencialmente em cursos superiores. Além disso, para viabilizar esse itinerário formativo, se está propondo alterar as regras do financiamento da educação pública, induzindo à realização de parcerias com o setor privado, retirando recursos da educação básica do País. Essa medida visa, claramente, atender aos interesses do empresariado e suas necessidades de exploração e lucro (RIBEIRO, 2016).

São muitas as insatisfações dos educadores e dos educandos com relação ao Novo Ensino Médio. São mudanças estruturais, instituídas por meio de uma Medida Provisória, sem diálogo com a sociedade em geral e principalmente com os mais afetados por essas mudanças: os alunos e os professores. Nesse sentido empenhar-se em problematizar essa reforma é uma tarefa urgente e essencial.

\section{Considerações finais}

As reflexões apresentadas no presente artigo explicitaram sobre os limites da atual reforma do Ensino Médio proposta por meio da Lei no 13.415/2017. Dentre os aspectos destacados na reflexão que integra o presente artigo enfatizou-se sobre a proposição de educação integral expressa na referida reforma.

Conforme foi possível compreender, a reforma que integra a educação integral no chamado Novo Ensino Médio tem como compromisso uma formação mais técnica e menos propedêutica, servindo dessa forma ao jogo de interesses que rege a sociedade do capital, pois contribui para a formação do homem produtivo, do homem massa, distanciando-se do conceito de ominilateralidade que pressupõe uma formação efetivamente integral. 
É nesse sentido que as reformas apresentadas no atual contexto político brasileiro, em especial as reformas para a educação - e aqui estamos nos referindo em específico a proposta de educação integral expressa no Ensino Médio -, não estão isentas de interesses e por vezes tais interesses estão a serviço do capitalismo, na medida em que priorizam a formação técnica e parcial voltadas apenas para a atuação do sujeito no mercado de trabalho, pois o capitalismo volta-se para a expansão e para a acumulação conforme indicou Mészáros (2002) tem na educação um instrumento que contribui para a sua legitimação e perpetuação.

\section{Referências}

BRASIL. Medida Provisória no 746, de 22 de setembro de 2016. Institui a Política de Fomento à Implementação de Escolas de Ensino Médio em Tempo Integral, altera a Lei no 9.394, de 20 de dezembro de 1996, que estabelece as =diretrizes e bases da educação nacional, e a Lei no 11.494 de 20 de junho 2007, que regulamenta o Fundo de Manutenção e Desenvolvimento da Educação Básica e de Valorização dos Profissionais da Educação, e dá outras providências. Diário Oficial da União, Brasília, DF, 23 set 2016. Seção 1, p. 1.

BRASIL. Medida Provisória no 746, de 22 de setembro de 2016. Exposição de Motivos. Brasília, DF: Câmara dos deputados. Disponível em: <http://www2.camara.leg.br/legin/ fed/medpro/2016/medidaprovisoria-746-22-setembro-2016-783654-exposicaodemotivos151127-pe.html> Acesso em: 28 jan 2017.

BRASIL. Ministério da Educação. Portaria no 1145, de 10 de outubro de 2016. Institui o Programa de Fomento à Implementação de Escolas em Tempo Integral, criada pela Medida Provisória $n^{\circ}$ 746, de 22 de setembro de 2016. Diário Oficial da União, Brasília, DF, 11 out 2016. Seção 1, p. 23-25.

DUARTE, Newton. Vigotski e o aprender a aprender crítica às apropriações neoliberais e pós-modernas da teoria vigotskiana. Campinas: Autores Associados, 2004

FERREIRA JR., Amarílio; BITTAR, Marisa. A educação na perspectiva marxista: uma abordagem baseada em Marx e Gramsci. Interface - Comunic., Saúde, Educ., v.12, n.26, p.635-46, jul./set. 2008.

JUNCKES, Cris Regina Gambeta. Educação integral, ampliação do tempo escolar e formação da criança: possíveis relações. UFPR: XI Ánped Sul, Curitiba, 2016. Disponível em: < http:// www.anpedsul2016.ufpr.br/wp-content/uploads/2015/11/eixo4_CRIS-REGINA-GAMBETA-JUNCKES.pdf >. Acesso em: 18 jan 2017.

MARX, Karl; ENGELS, Friedrich. Manifesto do Partido Comunista. vol 227. Porto Alegre: L\&PM Pocket, 2006.

MASSON, Gisele. As contribuições do método materialista histórico e dialético para a pesquisa sobre políticas educacionais. UCF: IX Anped Sul, 2012. Disponível em: <http://www.ucs.br/ etc/conferencias/index.php/anpedsul/9anpedsul/paper/viewFile/966/126>. Acesso em: 18 jan 2017.

MÉSZAROS, István. Para além do capital. São Paulo: Boitempo editorial, 2002.

MÉSZAROS, István. A educação para além do capital. 2. ed. São Paulo: Boitempo, 2014.

MINISTÉRIO DA EDUCAÇÃO. Disponível em: <http://portal.mec.gov.br/component/ content/article?id=40361> . Acesso em 18 jan 2017.

MOLL, Jaqueline. A agenda da educação integral: compromissos para sua consolidação como política pública. . In: MOLL, J. et al. Caminhos da educação integral no Brasil: direitos a outros tempos e espaços educativos. Porto Alegre: Penso, 2012. 
OCUPA PARANÁ. Disponível em: <http://www.ocupaparana.com.br/>. Acesso em: 18 jan 2017.

PONCE, Aníbal. Educação e luta de classes. São Paulo: Cortez, 1957.

RIBEIRO, Mônica. A medida Provisória 746 e o Ensino Médio em migalhas. Brasil de fato, Curitiba, p. 01, 15 out. 2016.

SAVIANI, Dermeval. O trabalho como princípio educativo frente às novas tecnologias. In: Novas tecnologias, trabalho e educação. Petrópolis: Vozes, 1994.

SAVIANI, Dermeval. Sistemas de ensino e planos de educação: o âmbito dos municípios. Educ. Soc., Campinas, v. 20, n. 69, p. 119-136, Dec. 1999.

SAVIANI, Dermeval. História das ideias pedagógicas no Brasil. 4. ed. Campinas: Autores Associados, 2013.

SILVA, Karen Cristina Jensen Ruppel da. Concepções que orientam atual agenda de educação integral no Brasil: uma análise de cadernos do "Programa Mais Educação". 2016. 180 f. Dissertação (Mestrado em educação) - Universidade Estadual de Ponta Grossa. Ponta Grossa, 2016.

SILVA, Mônica Ribeiro da; KRAWCZYK, Nora. Quem é e o que propõe o Projeto de Lei da reforma do Ensino Médio: entrevistando o Projeto de Lei 6.840/2013. In: AZEVEDO, José Clóvis de; REIS, Jonas Tarcísio. org. Ensino médio: políticas e práticas. Porto Alegre: Editora Universitária Metodista IPA, 2016.

TODOS PELA EDUCAÇÃO. s/d. Disponível em: <http://www.todospelaeducacao.org.br/ reportagens-tpe/32163/apenas-543-dos-jovens-concluem-o-ensino-medio-ate-os-19-anos/ >. Acesso em 18 jan 2017.

TONET, Ivo. Educação, cidadania e emancipação humana. 2. ed. Maceió: Edufal, 2013.

Notas

\footnotetext{
${ }^{1}$ Proposição e adoção de medidas como ajuste fiscal e reformas na educação, na previdência, nas leis trabalhistas, entre outras, sob o argumento de que elas são estratégias para solucionar a crise política e econômica, o desemprego, a inflação etc. ${ }^{2}$ Números atualizados até o dia 20 de outubro de 2016 pelo site do movimento Ocupa Paraná. Disponível
em: <http://ocupaparana.org/>.
}

${ }^{3}$ O Movimento Brasil Livre, bem como o Desocupa Paraná são exemplos de grupos que militaram contra as ocupações das escolas. De acordo com a versão eletrônica do jornal El País, tais grupos, adeptos ao anti-petismo, consideram que as ocupações foram motivadas por professores ligados a sindicatos e ao Partido dos Trabalhadores. Disponível em: <http://brasil.elpais.com/brasil/2016/10/29/politica/1477698231_566717. html>.

${ }^{4}$ Considerada assim por representar grande parte do referencial teórico dos artigos atuais sobre a temática. 
Novo ensino médio e educação integral: contextos, conceitos e polêmicas

sobre a reforma

* Doutoranda em Educação pela Universidade Estadual de Ponta Grossa, Ponta Grossa, Paraná, Brasil.

** Doutoranda em Educação pela Universidade Estadual de Ponta Grossa, Ponta Grossa, Paraná, Brasil.

\section{Correspondência}

Karen Cristina Jensen Ruppel da Silva - Universidade Estadual de Ponta Grossa. Av. Bonifácio Viléla - Centro. CEP: 84010-330. Ponta Grossa, Paraná, Brasil.

E-mail: jkarencristina@hotmail.com - audiboutin@hotmail.com

Recebido em 15 de dezembro de 2017

Aprovado em 20 de março de 2018 
